\title{
Radiosurgical Occurrence of Lumbar Disc Herniation Operated in Kinshasa / DRC
}

\author{
Frederick Tshibasu Tshienda ${ }^{1,}$,, Glennie Ntsambi Eba $^{2}$, Fidèle Nyimi Bushaba ${ }^{3}$, Wafa Mbarki ${ }^{4,7}$, \\ Tasnime Hamdeni ${ }^{4}$, Mounir Sayadi ${ }^{4}$, Benjamin Longo Mbenza ${ }^{5}$, Jean-Marie Mbuyi Muamba ${ }^{6}$ \\ ${ }^{1}$ Division of Diagnostic Imaging, University Hospital of Kinshasa, School of Medicine, University of Kinshasa, Kinshasa, Democratic \\ Republic of Congo \\ ${ }^{2}$ Department of Neurosurgery, University Hospital of Kinshasa, School of Medicine, University of Kinshasa, Kinshasa, Democratic Republic \\ of Congo \\ ${ }^{3}$ Department of Dental Medicine, Oral and Maxillofacial Surgery Division, University Hospital of Kinshasa, School of Medicine, University \\ of Kinshasa, Kinshasa, Democratic Republic of Congo \\ ${ }^{4}$ Laboratory Signal Image and Energy Mastery, University of Tunis, National High School of Engineering of Tunis, Tunis, Tunisia \\ ${ }^{5}$ Department of Internal Medicine, Division of Cardiology, University Hospital of Kinshasa, School of Medicine, University of Kinshasa, \\ Democratic Republic of Congo \\ ${ }^{6}$ Department of Internal Medicine, Division of Rheumatology, University Hospital of Kinshasa, School of Medicine, University of Kinshasa, \\ Kinshasa, Democratic Republic of Congo \\ ${ }^{7}$ Laboratory Signal Image and Energy Mastery, University of Sousse, National High School of Engineering of Sousse, Sousse, Tunisia
}

\section{Email address:}

fredtshibasu@gmail.com (Frederick T. T.), glen_neba@yahoo.fr (Glennie N. E.), fidelenyimi@yahoo.fr (Fidèle N. B.), mbarkiwafa416@gmail.com (Wafa M.), hamdeni.tasnime@gmail.com (Tasnime H.), mounir.sayedi@gmail.com (Mounir S.), longombenza@gmail.com (Benjamin L. M.), mbuyi_muamba@yahoo.fr (Jean-Marie M. M.)

${ }^{*}$ Corresponding author

\section{To cite this article:}

Frederick Tshibasu Tshienda, Glennie Ntsambi Eba, Fidèle Nyimi Bushaba, Wafa Mbarki, Tasnime Hamdeni, Mounir Sayadi, Benjamin Longo Mbenza, Jean-Marie Mbuyi Muamba. Radiosurgical Occurrence of Lumbar Disc Herniation Operated in Kinshasa / DRC. International Journal of Medical Imaging. Vol. 9, No. 3, 2021, pp. 130-140. doi: 10.11648/j.ijmi.20210903.11

Received: June 8, 2021; Accepted: July 9, 2021; Published: July 15, 2021

\begin{abstract}
Lumbar disc herniation (HDL) is a major public health problem in the world. Objectives: The study aimed to determine the clinical and radiological aspects of the lumbar disc herniation [LDH] operated in Kinshasa environments Hospital. Materials and methods: It was a well-documented 160 cases of LDH operated in Biamba Marie Mutombo hospital from January 2012 until December 2016 was evaluated. Results: The most interesting age group range from 31 to 50 years (68, $8 \%$ ) with a mean age of $44,7 \pm 12,3$ years in that Females were the most affected with 55.6\%. Sciatica L5 was found in $28.8 \%$ of cases compared to sciatica S1 (15.6\%) and left lateralization in 48, 1\%. As for imaging results, the posterolateral type was the most common with $53.8 \%$ of cases. The disc level: L4-L5 was the most affected in $61.1 \%$ of cases. The single LDH was the most common. The discrepancy between imaging and surgery results was $6.3 \%$ for medial herniated discs and $24.4 \%$ for posterolateral disc herniation. Conclusion: LDH is a pathological reality in hospitals of Kinshasa. The aspects found mainly corroborate literature observations. The discrepancy between imaging and surgery results was statistically insignificant.
\end{abstract}

Keywords: LDH, Magnetic Resonance Imaging, Computed Tomography Scan

\section{Introduction}

Lumbar disc herniation (HDL) is a major public health problem in the world [1]; of which disabling low back pain associated or not with sciatica is the clinical expression [2]. It is defined as a focal disc overhang containing, in addition to the annulus fibrosus, the nucleus pulposus, migrated from its central position to the periphery; more or less associated with the cartilaginous elements of the plateaus, the marginal listel, 
and the inflammatory tissue reacting to the presence of the nucleus pulposus [3]. According to the World Health Organization (WHO), HDL is the cause of $15 \%$ of absenteeism among heavy workers [1]. In France, low back pain is the most frequent reason for consultation in rheumatology with approximately $26 \%$ of hospitalized patients and $30 \%$ of outpatient consultations [4]. In the United States, 50 to $90 \%$ of Americans suffer from low back pain, which is the cause of severe occupational disability, and HDL is responsible for 1 to $30 \%$ of low back pain $[5,6]$. The incidence of HDL varies from one country to another; in Burkina Faso and Mali, $47 \%$ and $23.6 \%$ of cases, respectively, are reported $[7,8]$. The rate is quite low in Côte d'Ivoire and Tunisia, respectively $10.3 \%$ [9] and 2.2\% [10]. In the DRC, observations made in Kinshasa by Kutoloka in 2002 reported an incidence of $4.3 \%$ of patients per year [11]. HDL is undoubtedly a reason for absenteeism from work and an alteration in the quality of life due to the professional incapacity that it causes. In France, approximately 37,000 surgical interventions for herniated discs are reported each year [4, 12]. In England, the financial impact is estimated to be in the range of 16 to 50 billion US dollars [13]. However, it should be noted that medical imaging is useful in confirming the diagnosis before any surgical intervention. This is therefore an opportunity to ask the question about the concordance between the CT-MRI results of the lumbar disc herniation and the intraoperative diagnosis. This is all the more relevant because, to our knowledge, no previous study has so far defined the relevance of medical imaging in the management of lumbar disc herniation operated on in Kinshasa hospitals. Given the above, we propose to describe the radio surgical occurrence of HDL operated on in Kinshasa hospitals.

\section{Materials and Methods}

This was a mono-centric, retrospective, and documentary study carried out at the Biamba Marie Mutombo Hospital (BMMH) from January 2012 to June 2017, i.e. a period of 5 and $1 / 2$ years. The study concerned patients who had undergone a hernia repair. The sample was exhaustive and concerned all patients operated for HDL and having a crosssectional imaging examination (Scanner or MRI). All patients of Congolese nationality, male or female, aged at least 15 years, who underwent surgery for HDL and who had undergone a lumbar spinal CT and/or MRI scan on a Siemens somatom sensation 64-slice CT scanner and/or a Siemens TESLA 1.5 MRI were included. The CT or MRI was noninjected, obtained in helical acquisition. Of the 160 patients, one hundred and twenty had received a non-injected lumbar CT scan in the helical acquisition and forty patients received a non-injected lumbar MRI. The review of the CT and MRI examinations was performed by 4 physicians, including 3 radiologists with more than 8 years of experience and a young radiologist with 2 years of experience. Sociodemographic variables (sex and age), clinical parameters (radicular pathway, spinal radicular syndrome, neurological syndrome, lesion topography, and associated pathologies), inflammatory workup, blood count, CT-MRI results, and intraoperative results were systematically sought and evaluated. A pre-established data collection form was used to transcribe all the data related to each patient. Data collection was carried out in two stages: the first stage consisted of filling in the forms and the second stage consisted of transcribing the data on the data collection form. A Dell computer equipped with the following software: Epidata 3.1, SPSS version 21, Excel, and Word 2010 was used for data entry and analysis. Quantitative variables were expressed as means, standard deviations, or medians with extremes, and qualitative variables were expressed as percentages. The Pearson chi-square test was used for comparison of categorical variables. The significance level was set at 0.05 . The odds ratio (OR 95\% CI) studied the risk between the variables. The principle of confidentiality was observed during data collection

\section{Results}

Sociodemographic characteristics: the sample included 160 patient records, 89 of whom were women $(55.6 \%)$ and 71 men $(44.4 \%)$, with a sex ratio of 0.8 (Table 1$)$. The age range of 31 to 50 years was the most represented (68.8\%), with an average $( \pm$ SD) age of $44.7 \pm 12.3$ years, ranging from 16 to 79 years (Table 1 ). As for the radicular path, the table 2 showed that the left side was the most affected. Poorly systematized low back pain was the most frequent complaint with 64 cases $(40.0 \%)$, while 10 patients $(6.3 \%)$ presented a cruralgia the search for spinal syndrome by measuring the hand-to-ground distance revealed that in $57.9 \%$ of patients, the hand-to-ground distance was limited to $51 \mathrm{~cm}$ and more. The radicular syndrome was evaluated by looking the Lasègue sign; the latter was present in $66.75 \%$, absent in $8.125 \%$ and bilateral in $7.5 \%$ of cases. As for the neurological syndrome, the assessment of sensitivity was normal in $75 \%$ of patients and disturbed in $25 \%$. Motor skills were normal in $50.6 \%$ and disturbed in $49.4 \%$ Of the 160 patients, 51 cases was experienced of HDL rebellious to medical treatment. The hyperalgesia form was the most frequent in this series concerning the inflammatory workup and the haemogram, it appears from these examinations that no inflammatory marker was specific to HDL to the medical imaging examinations; standard radiographs were performed in all 160 patients, among which there were 32 trivial radiographs; disc pinching was the most encountered abnormality with $59.3 \%$. For the CT scan, anterior disc herniation was not found in any patient; all cases were of posterior type as summarized in Table 3 below. From this table, it appears that medial and posterolateral disc herniation were predominant in the proportions of $50 \%$ and $53.1 \%$ respectively. Out of a total of 160 patients, 48 patients $(30.0 \%)$ had undergone an MRI examination in addition to the CT scan. Of these 48 patients, $47.9 \%$ had posterolateral HD, 33.3\% had medial HD, and $18.8 \%$ had foraminal herniation. The anatomo-topographic distribution of the 
lesions, reveals that multiple locations of HDL were frequent in our series. The last two stages L4-L5 and L5-S1 were the most affected (Table 3). As for the associated pathologies: hypertrophy of the yellow ligament was frequently associated with lumbar disc herniation $62.5 \%$. Research into the relationship between the medical imaging diagnosis and the inflammatory balance revealed that the inflammatory balance was disturbed in 30 of the 160 patients. A statistically significant relationship was noted between the imaging result and the inflammatory assessment result $(\mathrm{p}=0.001)$. As for surgical management; All 160 patients had undergone laminectomy with hernia repair. Table 4 below reports the concordances and discordances found between imaging diagnosis and intraoperative findings. The discrepancies between imaging and intraoperative findings were 6.3 for medial HDL and $24.4 \%$ for posterolateral HDL. A statistically significant association was noted between HDL subtypes and intraoperative diagnosis $(\mathrm{p}<0.001$ (Table 4$)$.

Table 1. Distribution of patients by age and gender.

\begin{tabular}{|c|c|c|c|c|c|c|}
\hline \multirow{3}{*}{ Age range } & \multicolumn{4}{|l|}{ Sex } & \multirow{2}{*}{\multicolumn{2}{|c|}{ Total }} \\
\hline & \multicolumn{2}{|l|}{ Male } & \multicolumn{2}{|c|}{ Female } & & \\
\hline & $\mathbf{N}$ & $\%$ & $\mathrm{n}$ & $\%$ & $\mathbf{n}$ & $\%$ \\
\hline$\leq 30$ & 3 & 4,2 & 5 & 5,6 & 8 & 5,0 \\
\hline $31-40$ & 26 & 36,6 & 29 & 32,6 & 55 & 34,4 \\
\hline $41-50$ & 19 & 26,8 & 36 & 40,4 & 55 & 34,4 \\
\hline $51-60$ & 11 & 15,5 & 11 & 12,4 & 22 & 13,8 \\
\hline $61-70$ & 10 & 14,1 & 7 & 7,9 & 17 & 10,6 \\
\hline Total & 71 & 100,0 & 89 & 100,0 & 160 & 100,0 \\
\hline
\end{tabular}

Table 2. Distribution of patients according to radicular pathway, sensitivity, motricity, and results of biology, radiography, and lumbar CT.

\begin{tabular}{|c|c|c|}
\hline Parameters & $\mathbf{n}$ & $\%$ \\
\hline \multicolumn{3}{|l|}{ Root path } \\
\hline \multicolumn{3}{|l|}{ L5 } \\
\hline Left & 23 & 14,4 \\
\hline Right & 15 & 9,4 \\
\hline Bilateral & 8 & 5,0 \\
\hline \multicolumn{3}{|l|}{$\mathrm{S} 1$} \\
\hline Right & 8 & 5,0 \\
\hline Bilateral & 5 & 3,1 \\
\hline \multicolumn{3}{|l|}{ Poorly systematized } \\
\hline Left & 35 & 21,9 \\
\hline Right & 20 & 12,5 \\
\hline Bilateral & 9 & 5,6 \\
\hline \multicolumn{3}{|l|}{ truncated sciatica } \\
\hline Right & 3 & 1,9 \\
\hline Bilateral & 5 & 3,1 \\
\hline Cruralgia & 10 & 6,3 \\
\hline \multicolumn{3}{|l|}{ Sensitivity } \\
\hline Normal & 120 & 75,0 \\
\hline \multicolumn{3}{|l|}{ Hypoesthesia } \\
\hline L5 & 13 & 8,1 \\
\hline $\mathrm{S} 1$ & 12 & 7,5 \\
\hline \multicolumn{3}{|l|}{ Anaesthesia } \\
\hline L5 & 10 & 6,3 \\
\hline S1 & 5 & 3,1 \\
\hline \multicolumn{3}{|l|}{ Motor skills } \\
\hline Normal & 81 & 50,6 \\
\hline Paresis & 35 & 21,9 \\
\hline \multicolumn{3}{|c|}{ Clinical forms and LDH resistant to medical treatment } \\
\hline Hyperalgesia & 80 & 50,0 \\
\hline Paralyzing & 19 & 11,9 \\
\hline Ponytail syndrome & 10 & 6,3 \\
\hline Herniated discs resistant to medical treatment & 51 & 31,9 \\
\hline Inflammatory assessment & & \\
\hline
\end{tabular}




\begin{tabular}{lll}
\hline Parameters & $\mathbf{n}$ & $\mathbf{\%}$ \\
\hline Normal & 130 & 81,3 \\
Perturbed & & 12,5 \\
CRP increased & 20 & 6,2 \\
VS accelerated & 10 & 96,9 \\
Haemogram & & 3,1 \\
Normal & 155 & 20,0 \\
Perturbed & 5 & 59,4 \\
Radiography & & \\
Normal & 32 & 7,5 \\
Disc pinch & 95 & 8,8 \\
Transitional anomalies & & 4,4 \\
Lumbarization SI & 12 & \\
Sacralisation L5 & 14 & \\
Lumbar spinal rectitude & 7 & \\
\hline
\end{tabular}

Table 3. Distribution of patients according to LDH types and subtypes on CT.

\begin{tabular}{llll}
\hline Parameters & & Effective & \% \\
\hline $\begin{array}{l}\text { Diagnosis of imaging } \\
\text { Type of hernia }\end{array}$ & Subtype & - & \\
Anterior hernia & & & \\
Posterior hernia & Median Hernia & 80 & 50,0 \\
& Posterior lateral Hernia & 85 & 53,1 \\
& Foraminal Hernia & 5 & 3,1 \\
& Extra foraminal hernia & 5 & 3,1 \\
Number and level of disc levels affected & & & \\
Number of disc stages & Disc floor level & 55 & \\
& L4 - L5 & 35 & 34,4 \\
Unique & L5 - S1 & 90 & 21,9 \\
& Total & 10 & 56,3 \\
Double & L3 - L4, L4 - L5 & 45 & 6,3 \\
Triple & L4 - L5, L5 - S1 & 55 & 28,1 \\
\hline
\end{tabular}

Table 4. Diagnostic imaging and inflammatory findings.

\begin{tabular}{|c|c|c|c|c|c|c|c|}
\hline \multirow{3}{*}{ Diagnostic imaging } & \multicolumn{4}{|c|}{ Inflammatory assessment } & \multirow{2}{*}{\multicolumn{2}{|c|}{ Total }} & \multirow{3}{*}{$\mathbf{P}$} \\
\hline & \multicolumn{2}{|c|}{ Perturbed } & \multicolumn{2}{|c|}{ Normal } & & & \\
\hline & $\mathbf{n}$ & $\%$ & $\mathbf{n}$ & $\%$ & $\mathbf{n}$ & $\%$ & \\
\hline Median Hernia & 10 & 5,7 & 70 & 40,0 & 80 & 45,7 & \\
\hline Posterior lateral Hernia & 15 & 8,6 & 70 & 40,0 & 85 & 48,6 & \\
\hline Foraminal Hernia & 5 & 2,8 & 0 & 0,0 & 5 & 2,8 & $<0,001$ \\
\hline Extra foraminal hernia & 0 & 0,0 & 5 & 2,8 & 5 & 2,8 & \\
\hline Total & 30 & 17,1 & 145 & 82,9 & 175 & 100,0 & \\
\hline
\end{tabular}

Table 5. Comparative illustration between imaging diagnosis and intraoperative results.

\begin{tabular}{llll}
\hline Diagnosis imaging & Intraoperative diagnosis & $\mathbf{n} / \mathbf{\%}$ & $\mathbf{P}$ \\
\hline Median Hernia & Posterolateral sub ligamentary hernia & $5(6,3)$ & \\
& Median sub-ligamentary hernia & $75(93,7)$ & $<0,001$ \\
& Total & $80(100,0)$ & $1(1,2)$ \\
Posterolateral hernia & Bone growth compressing the roots & $5(5,8)$ \\
& Posterolateral ejected hernia & $60(69,8)$ & $<0,001$ \\
& Posterolateral sub-ligamentary hernia & $10(11,6)$ & $10(11,6)$ \\
Foraminal hernia & Ejected median hernia & $85(100,0)$ & $<0,001$ \\
& Median sub-ligamentary hernia & $5(100,0)$ & $<(100,0)$ \\
Extraforaminal hernia & Total & $5(100,0)$ & $<0,001$ \\
\hline
\end{tabular}




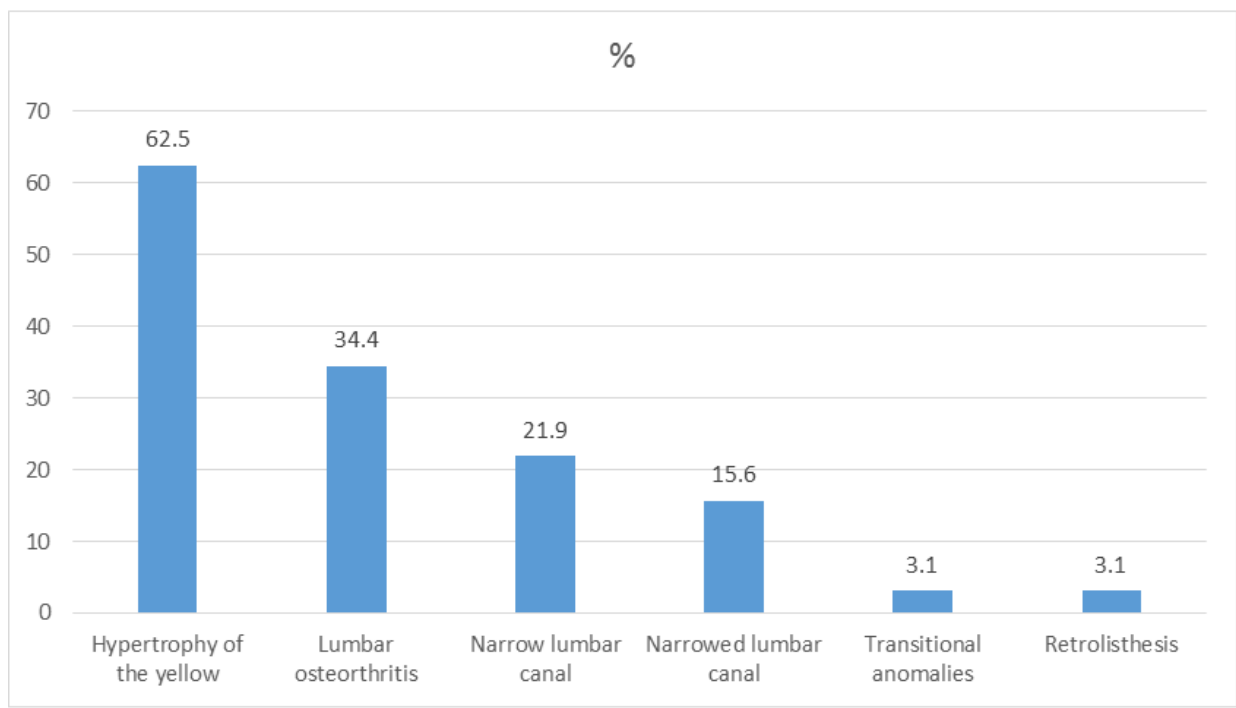

Figure 1. Pathologies associated with operated lumbar disc herniation.
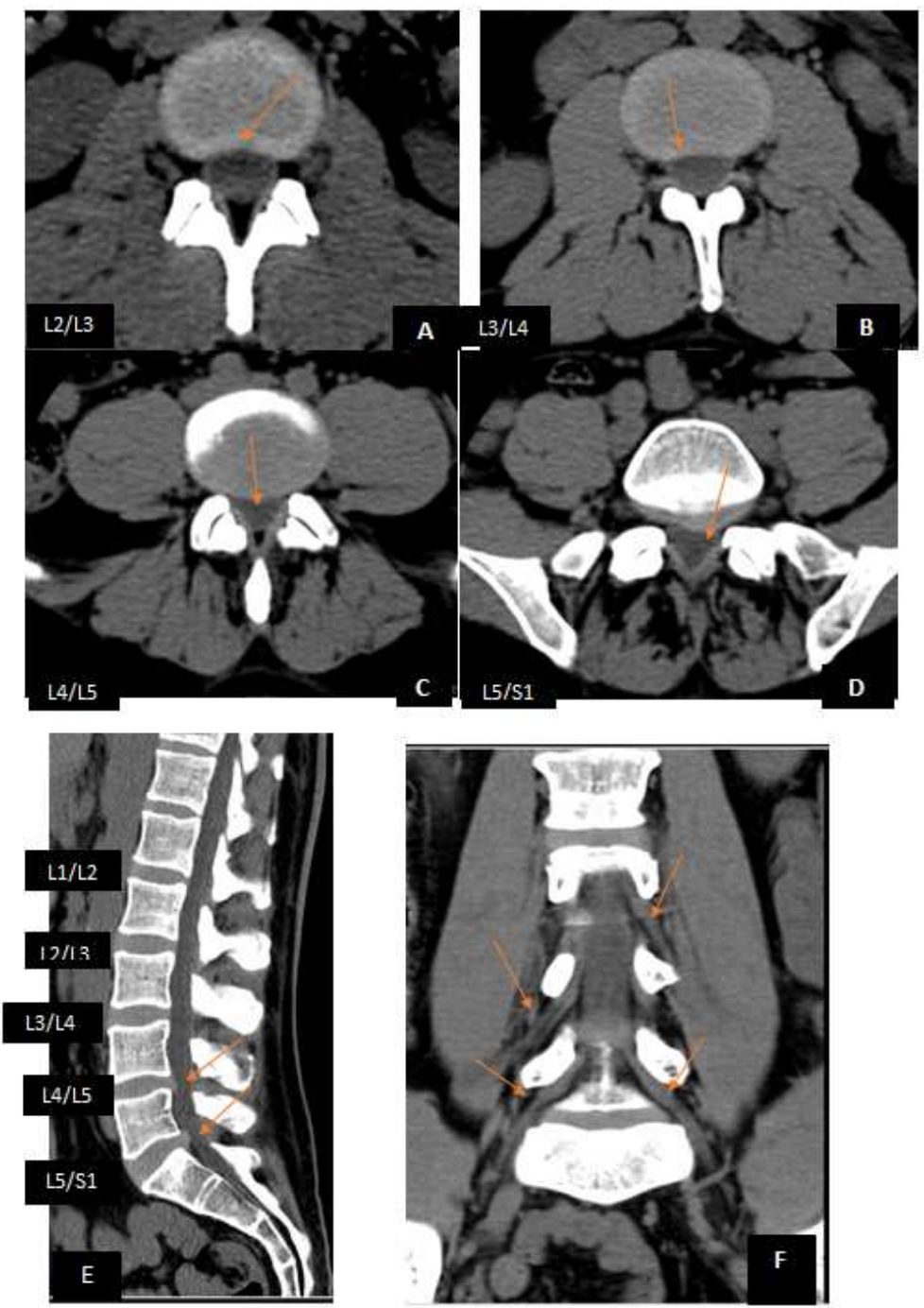

Figure 2. 55- year old patient with hyperalgesia low back pain of abrupt onset A. Axial soft tissue filter CT section at the L2-L3 level, showing a preserved posterior disc concavity; B. Axial soft tissue filter CT section at the L3-L4 level, showing a normal posterior disc concavity; C. Axial soft tissue filter CT section at the L4-L5 level, showing circumferential disc bulge with stenosis of the lateral recesses; D. Axial soft tissue filter CT section at the L5-S1 level, showing a posterolateral left disc protrusion with narrowing of the ipsilateral conjugation foramen; E. Soft tissue filter CT image, on a sagittal view; showing a bi-level disc protrusion at L4/L5 and L5/S1. Soft tissue filter CT image on coronal view, showing normal spontaneous nerve root caliber and density at S1 and L5; F. Soft tissue filter CT image on sagittal view; showing disc spur at L4-L5 and L5-S1. 


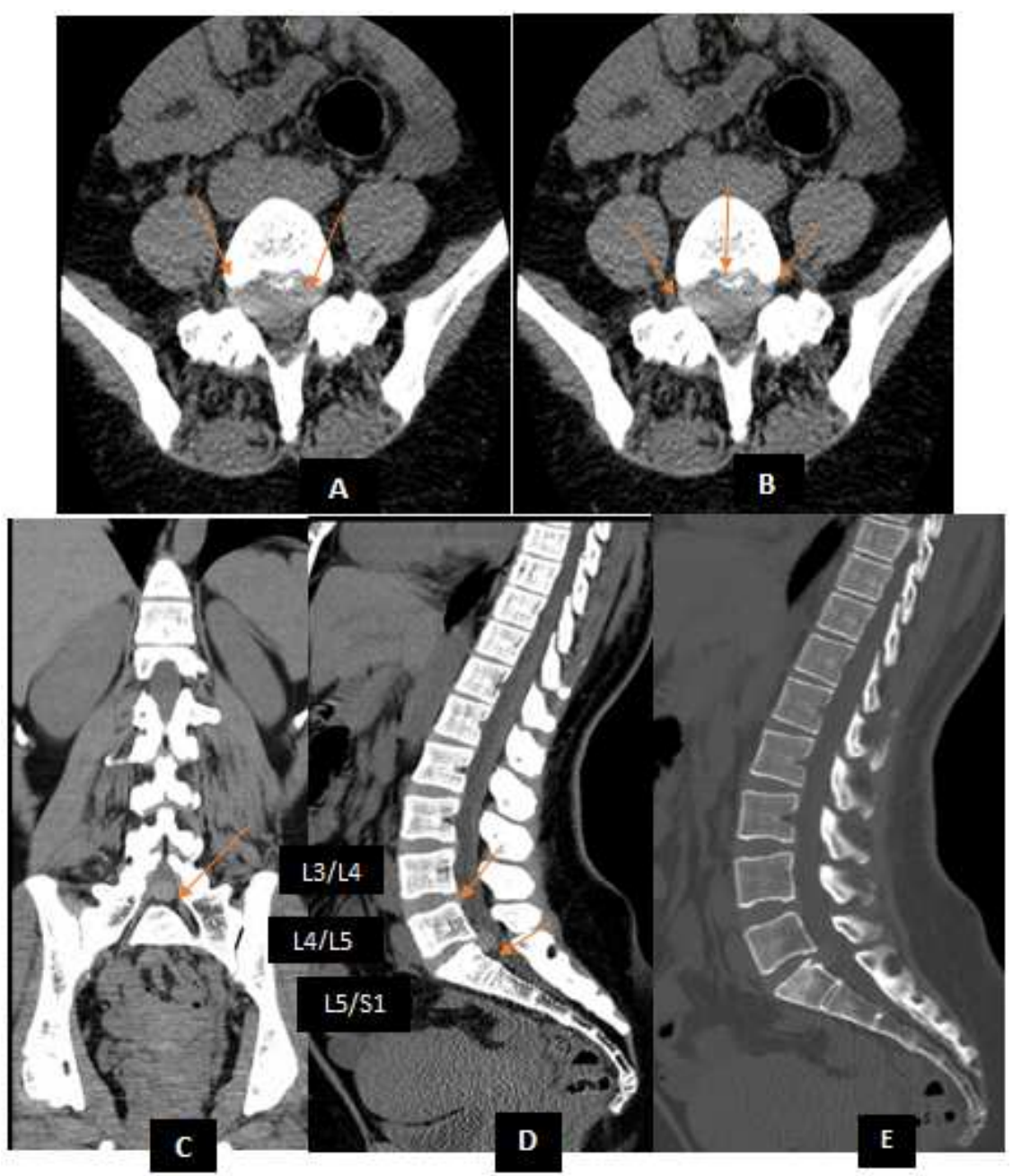

Figure 3. 37-years-old patient with sudden onset of right lumbosciatica. A And B. Axial CT sections, soft tissue filter at the L5-S1 level, showing medial, right Para median and ipsilateral foraminal disc protrusion with right lateral recess stenosis, right foraminal stenosis and disc-root impingement with the right L5 nerve root C. CT images of the lumbar spine on a coronal soft tissue filter view, showing a focal disc protrusion at L5/S1; D. CT images of the lumbar spine on a sagittal soft tissue filter view, showing a focal disc protrusion at the last two levels: L4-L5 and L5-S1 E. CT image if the lumbar spine on a bone filter view, showing no relevant abnormality.

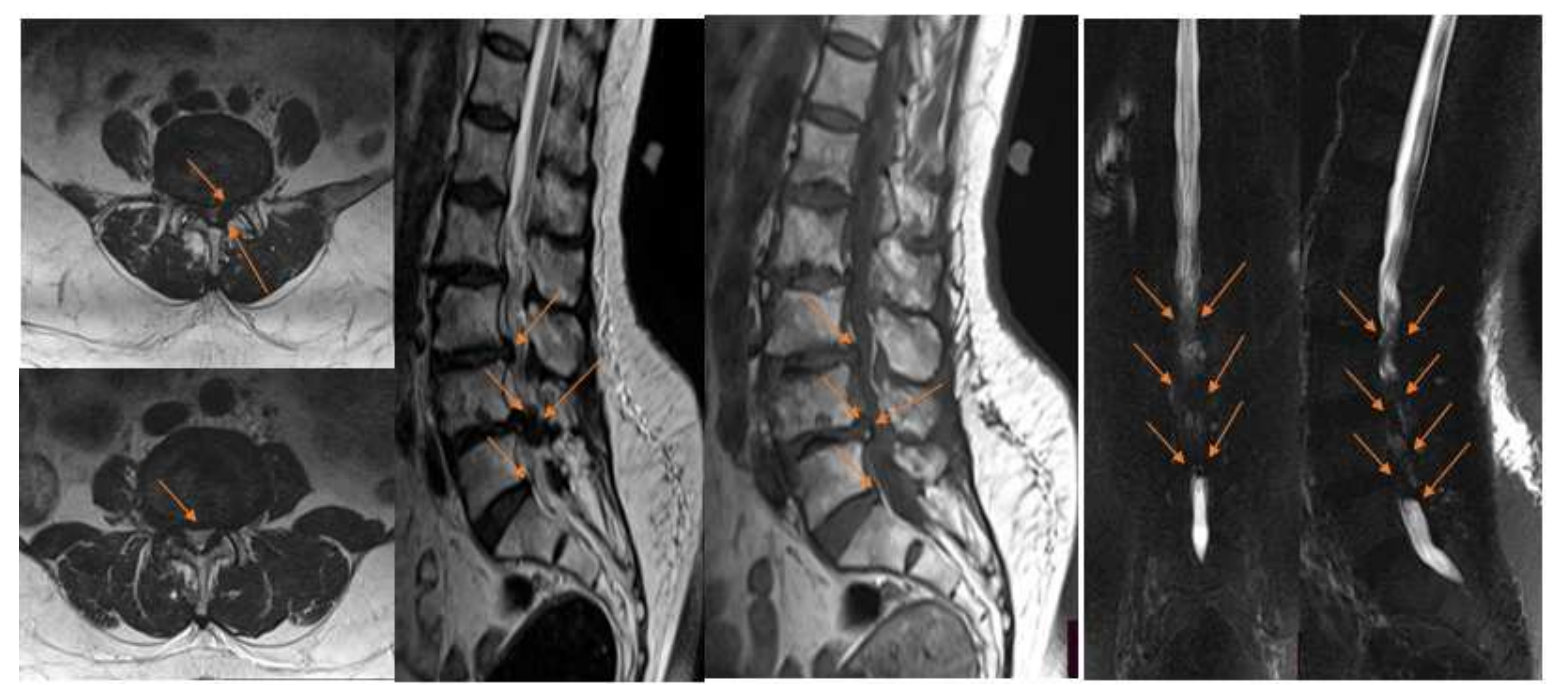

Figure 4. 68-years-old female patient with hyperalgesia low back pain with intermittent claudication. A: T2 TSE weighted axial section, passing through the L3/L4 disc with Pffirman D-type degeneration. B: T2 TSE axial section passing through the L4/L5 disc, showing a left para-medial disc protrusion with descending migration on Pffirman D-type disc degeneration. C. T2 TSE axial section through the L5/S1 disc, showing global disc degeneration; D. T1 TSEweighted lumbar spinal MRI images, showing focal disc overhang at the L2/L3, L3/L4 and L4/L5 levels; F and G: Lumbar spinal MRI Myelo sequence, on sagittal and coronal views, showing central narrowing of the lumbar canal. 


\section{Discussion}

The portrait of the Congolese from Kinshasa suffering from lumbar disc herniation is that of a female individual $(55.6 \%)$, aged $44.7 \pm 12.3$ years on average, complaining mainly of L5 lumbosciatica (28.8\%), more lateralized on the left $(14.4 \%)$, triggered by lifting effort and whose neurological disorders were marked by hypo and anesthesia respectively at (8.1 and 7.5\%), associated with motor disorders (49.4\%). Conventional radiography was pathological in $(80.0 \%), \mathrm{CT}$ in $(100 \%)$ and MRI in $(30.0 \%)$ of the operated patients. The analysis of the results had found statistically significant associations respectively (69.3\%) between the medical imaging results and the intraoperative results, (82.9\%) between the HDL subtypes and the results of the inflammatory assessment. This led us to conclude that this study corroborates the observations in the literature. Socio epidemiological profile: Age: This study showed that 110 patients out of $160(68.8 \%)$ were between 31 and 50 years old. The mean age was $44.7 \pm 12.3$ years with extremes ranging from 16 - 79 years? HDL was overwhelmingly a young adult condition. The latter would be exposed to heavy work; incriminated in the pathogenesis of HDL. Our results are very similar to those found in the literature. Indeed, low back pain due to HDL occurs most often in young adults aged 30 to 50 years [4]. Some small variations were noted according to the series, but most often, the age of the patients at the time of diagnosis is between 36 and 55 years old [4, 14-16]. At the Hubert Maga National University Hospital Center in Cotonou, Tononhi's studies showed a mean age of 44.9 years [4]. Tchuindjang found that the most affected age groups were between 31 and 60 years, with a predominance of the 41 to 50 years age group and a median age of 45.6 years [17]. Ouattara found a median age of 43.5 years with a predominance of the 40-49 years age group. Kutoloka in the DRC reported a mean age of 48.4 years $[11,16]$. Sex: in our series, 110 cases $(55.6 \%)$ were predominantly female out of a total of 160 patients, with a sex ratio of 0.8 in favor of women. We believe that the high participation of Congolese women in survival activities may push them to perform exertional activities that overload their lumbar spine. The high number of maternity could also play a role in the imbalance of the lumbar spine. Our results are close to those of a study carried out in Bamako in 2002, which showed a predominance of women with a sex ratio of 1.95; in contrast to the study carried out in Burkina Faso, where the sex ratio was 1.9 in favor of men [7, 8]. Our results are, on the other hand, in contradiction with certain data in the literature, which are unanimous on the male predominance of herniated discs in Mali, Africa and the rest of the world, with a sex ratio ranging from 1.4 according to Diarra $\mathrm{M}$ to 1.9 according to Tchuindjang K $[8,17]$. Clinical study: Mode of onset: In this study, 71 patients $(44.4 \%)$ presented with the progressive onset of HDL. This could be explained by a high rate of selfmedication with analgesics and anti-inflammatory drugs in our environment. It should be noted that HDL sciatica has two modes of onset; one acute and the other progressive. In the first, pain occurs immediately in a flash, associated with a more or less marked functional impotence. As for the second, it spreads over a few days and follows a history of low back pain or lumbago. In this series, the acute onset was noted in $25 \%$ of the cases, which is in line with the results of Mandour and Lazorthes with $27.5 \%$ and $28 \%$ of the cases, respectively $[18,19]$. On the other hand, the progressive onset of $44.4 \%$ in this series was far lower than the observations of Mandour and Deshayes who reported 58.8\% and $60 \%$ respectively $[18,20]$. This difference was probably because the mode of installation was not specified in our series in 49 patients (30.6\%). The mode of admission to the hospital in this series at $50.6 \%$ of the patients were as emergencies, against $49.4 \%$ admitted by appointment. This can be explained by the fact that the majority of the patients operated on, i.e. $68.2 \%$, presented symptomatic forms of HDL hernia (hyperalgesia, paralysis and cauda equina syndrome), found respectively in $50 \%, 11.9 \%$ and $6.3 \%$ of the cases, whereas HDL hernia that was rebellious to medical treatment was found in only $31.9 \%$ of cases. The radicular pathway: the study of the radicular pathways in our series showed a predominance of poorly systematized low back pain in 46 cases (28.8\%), followed by L5 in 46 cases (28.8\%) and $\mathrm{S} 1$ in 25 cases (15.6\%). This large number of poorly systematized low back pain could be explained by the fact that the neurological examinations were probably summary, performed by general practitioners. The frequent involvement of the L5 root could be explained by the vulnerability of the L5 root compared with the S1 root, whose lesion may evolve for a long time in a low-key manner before manifesting itself. Our data are in agreement with the results of Mandour and Lazorthes [18, 21]. The predominance of left lateralization was noted in this series in 77 cases $(48.1 \%)$ compared to the right side in 46 cases (28.8\%). We have no explanation to give on this subject. Bilateral sciatica was found in our series in $19.3 \%$ of cases. We have no particular reason to give for this finding. Nevertheless, our data are close to the results of Gandin who reported $16 \%$ of cases [22]. Physical examination: The spinal syndrome: low lumbar stiffness was assessed by the handground distance in all patients; 116 patients $(82.9 \%)$ had a distance greater than $30 \mathrm{~cm}$. This rate was slightly higher than that reported by Mandour (53.2\% of cases) [18]. The Lasègue maneuver was the most frequently explored procedure on neurological examination. It was positive in 147 patients $(91.9 \%$ ), of which $68.75 \%$ with homolateral positive Lasègue, $15.625 \%$ with contralateral positive Lasègue and $7.5 \%$ with bilateral positive Lasègue. As a result of its repercussion on the nerve root, the herniated disc reduces in most cases the normal sliding amplitude of the root in the inter disco-apophyseal pathway [23]. This is why it correlates with the degree of HDL progression [24]. For Klat $\mathrm{M}$ and Mbuyi $\mathrm{M}$, the first degrees of the Lasègue sign are the most decisive for the diagnosis of sciatica of disc origin [24]. A Lasègue sign lower than $25^{\circ}-30^{\circ}$ indicates 
severe sciatica. When the patient's sciatic pain is reproduced by elevation of the contralateral lower limb, it is a contralateral Lasègue. In Gandin and El Azhari, the Lasègue sign was positive in $75 \%$ and $87 \%$ of cases respectively [22, 25]. Neurological syndrome: Sensitivity study: one hundred and twenty patients (75\%) had normal sensitivity, 25 patients (15.6\%) had hypoesthesia, while anesthesia was found in 15 patients $(9.4 \%)$. These disorders concerned the L5 or SI territories (on the anterolateral aspect of the leg, the dorsum of the foot and the big toe in the case of L5 involvement, and on the Achilles tendon, the heel and the sole of the foot in the case of SI involvement). These sensory disorders were also found by Deshayes in 25\% of cases and by El Azhari in $42 \%$ of cases [20, 25]. Motor study: Segmental motor function was assessed in all patients of this series. Eighty-one patients $(50.6 \%)$ had no motor deficit, 35 patients $(21.9 \%)$ had paresis and 34 patients $(21.3 \%)$ had complete paralysis. Our results are in agreement with the observations of Dheshayes who reported paralyzing sciatica in $9.1 \%$ and paresis in $23.9 \%$ [20]. Similarly, Guieu reported paralyzing sciatica in $10 \%$ and paresis in 14\% [26]. As for Brement, he reported 5.8\% of paralyzing sciatica and $10.8 \%$ of paresis sciatica [27]. Clinical forms of common sciatica: Hyperalgesia sciatica: prohibits any spinal mobilization. The pain is excruciating, not soothed by decubitus. After radiological assessment and when it does not subside under medical treatment, surgical intervention is necessary. In our series, it was found in 80 patients $(50 \%)$. Our results are similar to those of Davis who reported $76 \%$ of hyperalgesia forms in his series [28]. Brement, on the other hand, reported a frequency of $24.16 \%$ [27]. Barhourhe, in a series of 266 patients, reported a frequency of $25.93 \%$ [29]. This high rate of hyperalgesia forms; helped to explain why nearly $50 \%$ of patients had an admission delay of more or less $\leq$ to 17.5 days. Paralytic forms: were observed in 19 patients (11.9\%) of our series. Generally speaking, paralyzing sciatica presents initially as common or hyperalgesia sciatica, then the pain disappears, giving way a motor deficit of sudden or subacute onset. The latter often concerns the anterolateral compartment of the leg. In some cases, electromyography can be used to quantify the motor impairment and to follow its evolution. Our observations are in line with those of Guieu [26] and Deshayes [20] who reported a frequency of $10 \%$ and $9.1 \%$ respectively. Barhoure [29] reported a frequency of $14.27 \%$. Cauda equina syndrome: was found in 10 patients $(6.3 \%)$. It is the result of compression of the roots of the cauda equina by a large HDL, often posteromedial. This syndrome remains rare both in the literature and in our series. Our observations are close to the data of Pierron [30] who reported a frequency of $5.4 \%$. Rafik $[31,32]$ reported a frequency of $2.7 \%$. Forms according to age: HDL surgery remains rare in elderly subjects. In our series, 3 patients $(1.9 \%)$ were aged 71 years or more, including 2 men and 1 woman. This could be explained by the fact that neurosurgeons and anesthesiologists avoid taking risks because surgery, as well as anesthesia at this age, remains very delicate. In children and adolescents, HDL was also rare. In our series, only one case was operated on at the age of 16 . Our results are close to those of Rafik [31, 32] and Mrabet [33] who reported respectively $1.1 \%$ and $3 \%$. Para clinical examinations: Inflammatory work-up and haemogram: out of 160 patients, $130(81.3 \%)$ had a normal inflammatory work-up. 30 patients (18.7\%) had a disturbing inflammatory balance, including 12.5 with an increased CRP and $6.2 \%$ with an accelerated SV. It should also be noted that the blood count was disturbed in $3.1 \%$ of cases. Of the 80 cases of medial HD, 10 cases (5.7\%), 85 cases of posterolateral HD, 15 cases (8.6\%) and 5 cases out of 5 of foraminal HD had a disturbing inflammatory balance. The study noted a statistically significant association between imaging diagnoses and inflammatory findings $(\mathrm{p}=0.001)$. However, it should be noted that HDL is a degenerative condition that does not positively influence the sedimentation rate [27, 33]. It should be noted that the accelerated SV and elevated CRP in some patients in our series could be due to other conditions not investigated or reported in the records. Some authors had also noted an elevated CRP level during HDL [34]. According to these authors, disc pathology would be marked by a systemic inflammatory response related to the degree of progression of the herniated mass. Medical imaging: Standard radiography: the results showed global disc pinching in 95 patients (59.4\%). The examination was normal in 32 patients $(20 \%)$. Transitional anomalies were found in 26 patients $(16.2 \%)$, while spinal straightness was objectified in 7 patients $(4.4 \%)$. Standard radiography is the first examination to be performed when medical treatment fails. El Azhari [25] and Czorny [35] also reported a global disc pinch in $32 \%$ and $25 \%$ of cases, respectively. Computed tomography (CT): posterior HDL was found in $100 \%$ of patients in our series. Medial HD was observed in 80 patients $(50.0 \%)$, posterolateral HD in 85 patients $(53.1 \%)$, foraminal $\mathrm{HD}$ in 5 patients $(3.1 \%)$, and extraforaminal herniation also in 5 patients $(3.1 \%)$. In our series, single disc herniation's were frequently found in 90 cases $(56.3 \%)$. The L4 - L5 disc level was the most affected in 55 cases $(34.4 \%)$. These results corroborate the work of Baddou and Kutoloka [11, 36]. The predominance of the L4L5 level could be due to the fact that this disc is probably more stressed than the L5-S1 level. Double disc herniation's were found in 55 cases $(34.4 \%)$ with a predominance at the L4-L5 and L5-S1 disc levels in 45 cases $(28.1 \%)$. These last two discs are the most mobile of the lumbosacral hinge, hence the predominance of involvement at their levels. Triple disc herniation's were found in 15 cases $(9.4 \%)$ at L3 - L4, L4 - L5 and L5 - S1. Our results agree with those of the literature, both for the disc levels and for the topography of the lesions. In Destandau [37], the stages (L3-L4, L4-L5 and L5-S1) were involved in $15 \%, 51 \%$ and $25 \%$ of cases, respectively. This confirms that the L4-L5 and L5-S1 discs are the most affected, because of the importance of the stresses and pressures exerted on them [38]. It should be noted that the first two discs: L1-L2 and L2-L3 were not affected in our series. Magnetic resonance imaging (MRI): in our series, 48 patients had undergone a lumbar CT-MRI scan, i.e. $30 \%$ of the cases. We did not note any discrepancy in the 
results between these two techniques. This can be explained by the small number of patients who underwent both examinations at the same time, which does not allow us to draw realistic conclusions. Associated pathologies: Our series showed that hypertrophy of the yellow ligament was the most frequently associated spinal pathology with $62.5 \%$ of cases, followed by narrow lumbar canal with $21.9 \%$ of cases. Transitional anomalies and retrolisthesis were the least common with $6.2 \%$ of cases. A statistically significant association was noted between the three subtypes of posterior HDL and yellow ligament hypertrophy with p-values of 0.022 (medial HDL), 0.001 (posterolateral HDL), and 0.003 (extra foraminal HDL), respectively. The Narrow lumbar canal may be primary or secondary. It would seem that the fibrosis occurring during any disc herniation would be at the origin of the formation of osteophytes and the hypertrophy of the facet joints, at the origin of the compression of the bony structures still called primary structures; we speak then of a primary narrow lumbar canal [2]. Hypertrophy of the yellow ligament, on the other hand, only affects the ligamentous structures of the spine, also known as secondary structures; hence the name secondary narrow lumbar canal. Lumbar osteoarthritis is the most frequent degenerative pathology. According to the literature, it constitutes more than a quarter of the etiologies of low back pain; however, this hypothesis was not confirmed in this series. Moreover, these three pathologies are degenerative pathologies of the spine, such as herniated discs. This is why their association is frequent. On the other hand, transitional anomalies of the lumbar hinge had a negligible percentage. A Confrontation between admission time and surgical procedure. Surgical treatment of HDL needed to be well nuanced in some cases. In this study, the concept of admission time and its comparison with the literature allowed us to identify three groups of operative indication: A timeless than or equal to 7 months: concerned $89.4 \%$ of the patients operated on for surgical emergencies, in particular hyperalgesia sciatica, paresis, paralysis and cauda equina syndrome. Our observations are in line with those of the literature, which report an admission time ranging from one week to 10 years, with a maximum of frequency between 1 month and 1 year [39]. A delay of 8-16 months: concerned $9.4 \%$ of patients operated on for dragging sciatica that had refused medical treatment. A delay greater than or equal to 16 months: included $1.3 \%$ of patients operated on for sciatica that was resistant to medical treatment. Comparison of imaging results with intraoperative results. The comparison of the results of medical imaging (CT-MRI) with those of surgery (intraoperative diagnosis) of the operated HDLs made it possible to establish the following: in relation to median hernias, out of a total of 80 operated cases, the study had noted a discordance of the results in 5 patients, i.e. $6.3 \%$. Concerning the posterolateral lumbar disc herniations, out of a total of 85 operated cases, a discrepancy was noted in 21 patients, i.e. $24.4 \%$. As for the foraminal and extraforaminal herniation's, the results were consistent both on imaging and intraoperatively. The other point of discordance was because the CT scan was silent in the face of ejected lumbar disc herniations, which were only revealed intraoperatively. The significant rate of discordance in the case of posterolateral lumbar disc herniations could be attributed either to an error in the assessment of the different disc areas by the radiologist or simply to a regression of the herniated volume in patients who had received antiinflammatory medical treatment before surgery.

Note that a statistically significant relationship was established between imaging and intraoperative findings with a value $(\mathrm{p}<0.001)$.

Merits and weaknesses of the study: this study is first conducted in a hospital setting in Kinshasa and has allowed setting $\mathrm{t}$ the milestone of a confrontation between the radiological and per operative results of the operated HDL. This would help to avoid unjustified surgical indications and insufficient diagnoses in terms of imaging in our environment. However, we recognize that it has some weaknesses including:

Lack of accuracy of some clinical data in a larger number of patients. The small number of patients who underwent the MRI examination. The absence of a prospective study allowing the rereading of certain images of the examinations carried out with a view to diagnostic requalification.

\section{Conclusion}

The present study revealed the clinical, radiological and therapeutic aspects of LDH operated in hospitals in Kinshasa. It outperforms the results founds in the literature. It allowed us to compare the results of medical imaging with those of surgery. It turned out that, LDH is the prerogative of young patients, 110 patients $(68.8 \%)$ with a peak between the age groups of 31 to 50 years. A slight female predominance was observed in 89 cases, with a sex ratio of 80 men per 100 women. The effort of uprising was more incriminated as the trigger of the pathology disc. Sciatica L5 was more common with lateralization preferentially on the left. Floors L4-L5 and L5-S1 were the most affected. Posterolateral LDH was the most common subtype with $53.1 \%$. The discrepancy between the results of the imaging and those of the surgery was statistically insignificant $(6.3 \%)$ for median LDH and $24.4 \%$ for posterolateral $\mathrm{LDH}$

\section{Protection of Human and Animal Rights}

The authors declare that this study did not involve experiments on patients, subjects, or animals.

\section{Confidentiality of Data}

The authors declare that this study does not contain any personal data that could identify the patient or subject.

\section{Funding of the Study}

This study did not receive specific funding from any public or private institution. 


\section{Contribution and Responsibility of the Authors\&}

1. Dr. Frederick Tshibasu Tshienda: writing, proofreading.

2. Professor Glennie Ntsambi Eba: proofreading.

3. Engineer Wafa Mbarki: writing, proofreading

4. Engineer Tasnime Hamdeni: proofreading

5. Professor MOUNIR Sayadi: proofreading.

6. Professor Fidèle Nyimi Bushab: proofreading.

7. Professor Benjamin Longo Mbenza: writing, proofreading

8. Professor Jean-Marie MBUYI. Mwamba: writing, proofreading

\section{Conflict of Interest Statement}

All the authors do not have any possible conflicts of interest.

\section{References}

[1] Diseases WEC on I and C of W-R, Organization WH. Identification et prévention des maladies liées à la profession: rapport d'un Comité d' experts de l' OMS [réuni à Genève du 28 novembre au 2 décembre 1983]. 1985. Genève: Organisation mondiale de la Santé https://apps.who.int/iris/handle/10665/40231. Accessed 28 April 2021.

[2] Baron R, Binder A, Attal N, Casale R, Dickenson AH, Treede R. Neuropathic low back pain in clinical practice. Eur J Pain Lond Engl. 2016; 20 (6): 861-873.

[3] Manuel du Résident. Radiodiagnostic-NeuroradiologieAppareil locomoteur. Tsunami. 2009.

[4] Tonnonhi C. Les hernies discales au CHU Hubert Maga de Cotonou a propos de 78 cas. 2004.

[5] Rasmussen C, Nielsen GL, Hansen VK, Jensen OK, Schioettz-Christensen B. Rates of lumbar disc surgery before and after implementation of multidisciplinary nonsurgical spine clinics. Spine. 2005; 30 (21): 2469-2473.

[6] Deyo RA. Back surgery--who needs it? N Engl J Med. 2007; 356 (22): 2239-2243.

[7] Millogo A, Bamouni AY, Taoko A, Ki-Zerbo G, Sawadogo A, Yameogo A, et al. LOMBOSCIATIQUES: PROFIL RADIOCLINIQUE ET ETIOLOGIQUE AU CENTRE HOSPITALIER DE BOBO-DIOULASSO (BURKINA FASO). Médecine Afr Noire. 1999; 4.

[8] Diarra M. Etude des pathologies neurochirurgicales opérées dans le service d'ortho-traumatologie de l'Hopital Gabiel Touré à propos de 106 cas. 2002.

[9] KOUAKOU N, N'ZUE (M.) K, AKISSI (L.) N, ETI (E.), DABOIKO (J. C.), GABLA (A.), et al. Données épidémiologiques élémentaires sur la rhumatologie en milieu hospitalier Ivoirien. Données Épidémiologiques Élémentaires Sur Rhumatol En Milieu Hosp Ivoir. 1994.

[10] Elsevier. Prévalence et facteurs associés à la sciatique commune dans une population urbaine tunisienne. EM-
Consulte. https://www.emconsulte.com/article/52521/prevalence-et-facteurs-associes-ala-sciatique-com. Accessed 28 April 2021.

[11] Kutoloka M, Beltchika A, Fumu P. Aspects épidémiologiques et cliniques de la hernie discale lombaire aux Cliniques Universitaires de Kinshasa. Annales africaines de médecine. 2009. https://anafrimed.net/aspects-epidemiologiques-etcliniques-de-la-hernie-discale-lombaire-aux-cliniquesuniversitaires-de-kinshasa/. Accessed 30 April 2021.

[12] Sandjon D. Coût de la prise en charge des malades opérés dans le service de traumatologie et d'orthopédie du CHU Gabriel Touré de Janvier à Juin 2003. A propos de 130 cas. 2004.

[13] Daste C, Boisson M, Laclau S, Lefèvre-Colau M-M, Rannou F, Nguyen C. Traitements intradiscaux. Rev Rhum Monogr. 2020; 87 (2): 122-128.

[14] Berney J, Pretre JM, Kostli A. Facteurs épidémiologiques de la hernie discale lombaire. Journal neurochirurgie. 1990; 354 365 .

[15] Guyot-Drouot MH, Cortet B. Spondylodiscites. Revue du praticien. Rev Prat. 1996; Tome 10: 343.

[16] Diomande M, Ouattara B, Eti E, Gbane-Kone M, Ahoty F a. D, Djaha KJM, et al. LA HERNIE DISCALE LOMBAIRE AU CHU DE COCODY (ABIDJAN): ASPECTS EPIDEMIOLOGIQUES, CLINIQUES, RADIOLOGIQUES ET THERAPEUTIQUES. Rev Afr Malgache Rech Sci Santé. 2013; 1 (1).

http://publication.lecames.org/index.php/sante/article/view/42. Accessed 28 April 2021.

[17] TCUINDJANG K. Aspects épidémiologique, clinique et thérapeutique des hernies discales opérées dans le service de traumatologie et d'orthopédie du CHU Gabriel Toure. 2003.

[18] Mandour A. Les sciatiques par hernie discale au service de neurochirurgie du CHP de Meknès à propos de 102 cas. 2000.

[19] Dreiser R, Maheu E, Ghozlan R. Etude épidémiologique des stratégies diagnostiques et thérapeutiques dans les lombalgies et dorsalgies subaiguës et chroniques en médecine ambulatoire. Comparaison des attitudes en médecine générale et en rhumatologie. Rev Rhumatol. 1997; (64): 27-36.

[20] Deshayes P, Baron J, Leloyet X. Résultats du traitement médical en milieu hospitalier des sciatiques d'origine discale. Rev Rhum. 1981; (48): 7-9.

[21] Lazorthes Y, Richaud J, Roguer B. Sciatiques chirurgicales et chimionucléolyse. Neurochirurgie. 1985; 471-493.

[22] Gandin J, Lamoureux G, Boye P. Bilan critique du traitement chirurgical de 600 lombosciatiques: Orientation diagnostique et thérapeutique. Chirurgie. 1982; 108: 311-321.

[23] Kapandji AI (1928-2019) A. Physiologie articulaire: schémas commentés de mécanique humaine. 1972. Maloine. Paris.

[24] Klat M, Mbuyi M. Guide diagnostique en rhumatologie. 1989; 250-261.

[25] El azhari A, El kamar A, Ouboukhlik A. La sciatique paralysante par hernie discale. Rev Mar Méd St. 1992; 14: 39 41.

[26] Guieu R, Roussel P, Sedan R. Réflexe nociceptif de flexion de la jambe. La presse médicale. 1996; 22. 
[27] Brement J. A propos de 120 sciatiques par hernie discale opérées au service de neurochirurgie du Centre hospitalier Chambéry. 1977; 78.

[28] Davis RA. A long-term outcome analysis of 984 surgically treated herniated lumbar discs. J Neurosurg. 1994; 80 (3): 415-421.

[29] BARHOURHE O. Sciatique par hernie discale en milieu militaire au service de neurochirurgie CHU IBN Roch de casablanca. 1996.

[30] Pierron D, Fahim R, Halimi P, Doyon D. La place de l'examen tomodensitométrique dans le diagnostic des complications de la chirurgie discale lombaire. J Radiol. 1985; 66: 8-9.

[31] Rafik M. Sciatique par hernie discale à propos des 180 cas. 1990.

[32] Hammami M, Sahnoun N. Étude rétrospective concernant la prise en charge chirurgicale des lombosciatiques communes dans le Département d'Orthopédie de Tataouine, Tunisie: à propos de 44 cas. Pan Afr Med J. 2020; 35. doi: 10.11604/pamj.2020.35.103.22510.

[33] Mrabet H. Sciatique par hernie discale au CHU Ibn Rochd de Casablanca à propos de 278 cas. 1994.
[34] Kim NH. Anterior interbody fusion in the treatment of the lumbar herniated nucleus pulposus. Yonsei Med J. 1999; 40 (3): 256-264.

[35] Czorny A, Forloudou P, Kilik C. Les hernies discales lombaires de l'enfant; à propos de 12 cas. Neurochirurgie. Neurochirurgie. 1988; 34: 389-393.

[36] BADDOU S. La prise en charge chirurgicale de la sciatique par hernie discale lombaire Expérience du service de neurochirurgie du CHU Mohammed VI de Marrakech sur une période de 10 ans. 2013.

[37] Destandau J. Aspects techniques de la chirurgie endoscopique des hernies discales foraminales lombaires; A propos de 191 cas. Neurochirurgie. 2004; 50: 6-10.

[38] Deyo RA, Mirza SK. Trends and variations in the use of spine surgery. Clin Orthop. 2006; 443: 139-146.

[39] Zufferey P, Cedrashi C, Vischer T. Prise en charge hospitalière chez des patients lombalgiques: Facteurs prédictifs de l'évolution à deux ans. Rev Rhumatol. 1998; 65: 346-354. 